\title{
Optimized microwave digestion procedure for cadmium analysis of mussel samples
}

\author{
M.C. Yebra* and M.F. Enríquez \\ Department of Analytical Chemistry, Nutrition and Bromatology, Chemistry Faculty, University of Santiago, \\ 15706-Santiago de Compostela, Spain
}

\begin{abstract}
A simple and rapid acid sample digestion method by microwave heating in high pressure teflon bombs is reported for the determination of cadmium in mussels by flame atomic absorption spectrometry (FAAS) coupled on-line with a flow-injection preconcentration system. Tests concerning the digestion time, the power of the microwaves and the amount of nitric acid were studied with the National Research Council of Canada lobster hepatopancreas marine (Tort-1) as certified reference material. Using 2 min of digestion time and $2 \mathrm{~mL}$ of nitric acid, the complete dissolution of $0.2 \mathrm{~g}$ of freeze dried sample is possible. The analytical results, obtained with calibration graph as well as by the standard addition method, were agreed well with the certified value of the reference material. This procedure was applied to the determination of cadmium in mussel samples from estuaries in Galicia, Spain.
\end{abstract}

Key words. Microwave acid digestion — cadmium — mussels — flame atomic absorption spectrometry.

\section{Introduction}

The determination of cadmium and other trace metals in foods such as mussels provides information on the extent of aquatic ecosystems contamination, because these bivalves have been widely used as bioindicators of coastal contamination [1], and lead to an evaluation of their suitability for human consumption. Analysis of cadmium in biological and food samples traditionally has been performed by atomic absorption spectrometry. This requires a sample preparation before photometric identification. Decomposition of the organic matrices of these samples is a neccesary preliminary task for accurate determination of trace elements, because a complete or partial destruction or removal of the organic matrix is required to minimize chemical and/or physical interferences. Exceptions to this are certain beverages, to which it is possible to analyse directly without sample pretreatment. Therefore, digestion of the organic matter is a requisite for cadmium analysis in mussel samples. A great number of wet and dry ashing methods are known, but it is generally considered that dry ashing causes a loss of cadmium at temperatures over $500{ }^{\circ} \mathrm{C}$ [2-3], and wet digestions are tedious and time consuming. Microwave energy is currently used, since their implementation results in the improvement of existing processes such as digestion. The activation of processes by exposure to microwaves gives rise to faster and cleaner reactions when compared to conventional heating. This type of radiation is characterised by a high penetration effect into the materials, easy handling and rapid energy transfer to the whole sample without surface overheating, which reduces the digestion time to a few minutes [4-5]. The vessels used for microwave acid digestion can be low [6-7] and high pressure bombs [8]. With high pressure bombs, the pressures and temperatures needed for the total digestion of the sample are reached very quickly, and volatile elements as cadmium are not loss from these sealed vessels.
The purpose of this paper is to study the digestion of mussel samples using microwave energy in high pressure bombs with nitric acid for cadmium determination by a continuous flow injection system, including a preconcentration ion-exchange process, coupled to a flame atomic absorption spectrometer similar to that reported by Cespón-Romero et al. [9].

\section{Experimental}

\section{Apparatus}

To homogenize the samples an Ultra-Turrax T25 (Janke and Kunkel, GmbH and Co. K) and an Omni-Mixer and Homogenizer (Omni International, USA) were used. The homogenized samples were freeze-dried with the Bench Top Shell Freezer, model 77570, 7757-01 (Labcondo Corporation, USA). The digestion was carried out in a Parr 4782 Microwave Digestion Bomb (Parr Instrument Corporation, USA), which is designed specifically for microwave heating. The bomb is made with a new, highstrength microwave-transparent material to enclose a chemically inert teflon sample cup of $45 \mathrm{~mL}$. A microwave oven, Portland model N: KOR-1137 was used throughout. A Perkin Elmer 5000 atomic absorption spectrometer furnished with a cadmium hollow-cathode lamp was used. The instrument was set at $228.8 \mathrm{~nm}$. The acetylene flow-rate was $2.0 \mathrm{~L} \mathrm{~min}^{-1}$ and an air flow-rate of $17.0 \mathrm{~L} \mathrm{~min}^{-1}$ was employed to ensure an oxidizing flame. The aspiration flowrate of the nebuliser was adjusted to be the same as the flowrate of the FI channel. The spectrometer output was connected to a Perkin Elmer 50 servograph recorder with a range of $5 \mathrm{mV}$. The signals measured were the heights of the absorbance peaks. A Crison standard $\mathrm{pH}$ meter with electrode Ingold U 455 was used. The flow system is similar to that reported previously [9]. Materials and vessels used for trace analysis were kept in $10 \%$ nitric acid for at least $48 \mathrm{~h}$ 
and subsequently washed three times with ultrapure water before use.

\section{Reagents and solutions}

All chemicals were of analytical-reagent grade. A standard solution of $1000 \mu \mathrm{g} \mathrm{mL}-1$ cadmium(II) was prepared from $\mathrm{Cd}$ (II) nitrate in $0.5 \mathrm{M}$ nitric acid (BDH Chemicals, Poole, England). From this solution, other diluted standard solutions were prepared daily. Nitric acid (Merck, p.a.). Ammonia, 25\% (Merck, p.a.).The certified reference material used was TORT-1 (lobster hepatopancreas marine) from the National Research Council of Canada. Ultrapure water of $18.3 \mathrm{M} \Omega \mathrm{cm}^{-1}$ resistivity obtained from a Milli- Q water purification system (Millipore) served for dilution and washing, respectively.

\section{Procedure}

Mussel samples were triturated, homogenized, freeze dried, and then kept in clean, dry containers. After pulverization, and $24 \mathrm{~h}$ dried at $100{ }^{\circ} \mathrm{C}$, about $0.2 \mathrm{~g}$ of mussel sample was weighed in the teflon part of the bomb, $2 \mathrm{~mL}$ of concentrated nitric acid was added, and after closing the bomb, this was heated at $696 \mathrm{~W}$ for 2 minutes in the microwave oven. The bomb was then cooled in a water bath for about 20 minutes and then, was opened carefully in a fume cupboard. The solution was transferred into a $25-\mathrm{mL}$ vessel. The $\mathrm{pH}$ was adjusted with ammonia to 5 , the optimum $\mathrm{pH}$ for $\mathrm{Cd}$ preconcentration on the chelating resin placed on the flow injection system and then, diluted to $25 \mathrm{~mL}$ with ultrapure water in a volumetric flask (reference material was diluted to $250 \mathrm{~mL}$ ). Cadmium was continuously preconcentrated and determined by flame atomic absorption spectrometry. The flow injection system achieved a preconcentration factor of 16 with a sample volume of $3.4 \mathrm{~mL}$.

After each digestion procedure, the bomb was cleaned by adding $1 \mathrm{~mL}$ of concentrated nitric acid and placing it in the microwave oven for 2 minutes. After cooling the acid was removed and bombs were rinsed with ultrapure water.

\section{Results and discussion}

Nitric acid has been chosen because of its ability to oxidize the organic matter with few interferences in the flame atomic absorption spectrometry and its easiness to carry out the sample digestion.

To optimize microwave acid digestion, three parameters were studied: the digestion time the power of microwaves, and the amount of nitric acid added. In all instances, series of four replicates of $0.2 \mathrm{~g}$ of the certified reference material TORT-1 were sampled. Digestion time was studied at 1 , $2,3,4$, and 5 minutes and respectively to the following powers: 393, 495, 696 and $846 \mathrm{~W}$, with a nitric acid volume of $3 \mathrm{~mL}$. As can be seen in figure 1, the digestion was complete after 4 minutes at a microwave power of $393 \mathrm{~W}, 3 \mathrm{~min}-$ utes at $495 \mathrm{~W}$ and 2 minutes at 696 and $846 \mathrm{~W}$. Selecting as criteria minimum digestion time and minimum microwave power, a time of 2 minutes and a power of $696 \mathrm{~W}$ were chosen. $1 \mathrm{~mL}$ of acid was not sufficient for complete digestion, the organic matter was totally destroyed using since $2 \mathrm{~mL}$ nitric acid, but with larger volumes the $\mathrm{pH}$ adjustment was

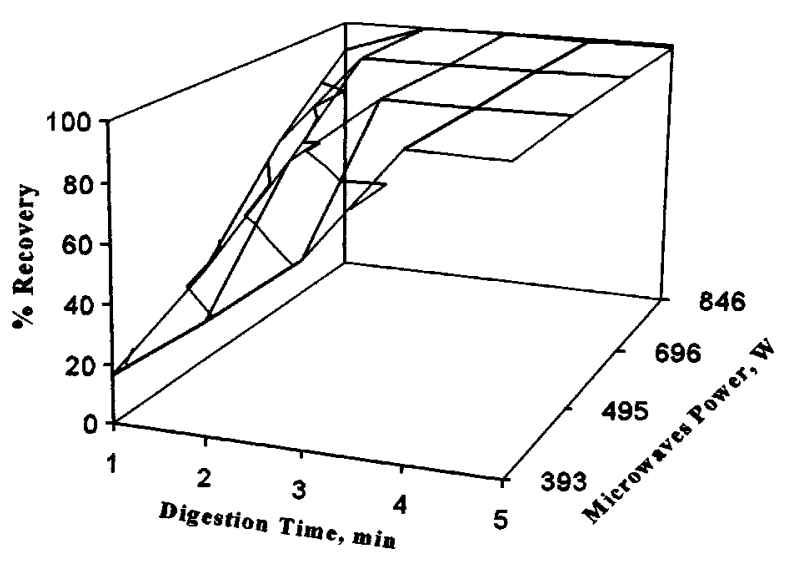

Fig. 1. Response surface for the optimization of microwave diges tion.

difficult. Therefore, a volume of nitric acid of $2 \mathrm{~mL}$ was selected.

\section{Calibration graphs}

Calibration graph was run $(n=7)$ under the optimal conditions, measuring standards aqueous solutions containing between $0-100 \mu \mathrm{g} \mathrm{L}^{-1} \mathrm{Cd}(\mathrm{II})$. The calibration curve obtained was: $A=8.1 \times 10^{-4}+2.2 \times 10^{-3}[\mathrm{Cd}(\mathrm{II})], r=0.999$ (where $A=$ absorbance). To study the possible matrix effect in the determination of cadmium, the standard addition method was also performed. $10 \mathrm{~mL}$ of diluted reference material were added to standard solutions contained 0,10 , $20,30,40,50$ and $60 \mu \mathrm{g}$ of cadmium. The $\mathrm{pH}$ was adjusted with ammonia to 5 and then, addition solutions were diluted to $25 \mathrm{~mL}$ with ultrapure water in a volumetric flask. The addition curve obtained was $A=0.017+2.1 \times 10^{-3}[\mathrm{Cd}(\mathrm{II})]$, $r=0.999$. The direct calibration and standard addition slopes were similar, and so direct calibration was used for all sample measurements.

\section{Precision and accuracy}

The precision of the procedure calculated for five replicate analysis of the certified reference material TORT-1 (lobster hepatopancreas marine) from the National Research Council of Canada was $1.4 \%$, expressed as coefficient of variation. To study the accuracy of the method, the certified reference material with a cadmium content of $26.3 \pm 2.1 \mu \mathrm{g} \mathrm{g}^{-1}$ was analysed. The $\mathrm{Cd}(\mathrm{II})$ contents obtained were: $27.9,27.9$ and $26.4 \mu \mathrm{g} \mathrm{g}^{-1}$ (mean \pm S.D.: $27.4 \pm 0.8 \mu \mathrm{g} \mathrm{g}^{-1}$ ), which agrees with the certified value.

\section{Determination of cadmium in mussel samples}

Analysis of cadmium in mussel samples from Galician (Spain) estuaries was performed by the proposed methodology. Results were obtained in three individual determinations and blanks were treated in the same way as the samples. The results obtained are shown in figure 2 . None of the concentrations of cadmium in all mussel samples analysed were higher than the maximum acceptable limit for seafoods (Cd should not exceed $\left.1 \mu \mathrm{g} \mathrm{g}^{-1}[10]\right)$, which does 


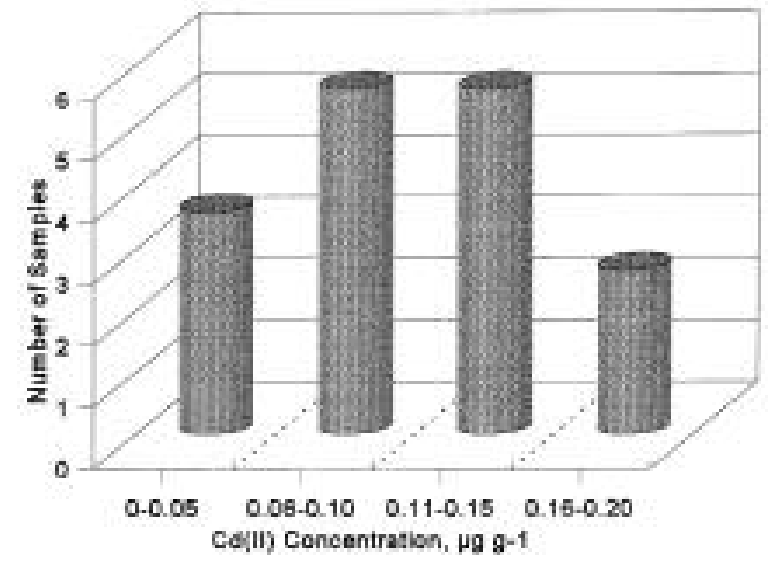

Fig. 2. Determination of $\mathrm{Cd}$ in mussel samples from Galician (Spain) Estuaries.

not represent any risk for health and indicates that their breeding areas were not polluted by cadmium.

\section{Conclusions}

The feasibility of high pressure dissolution with microwave energy of a mussel sample has been demonstrated. The pro- cedure for digestion of organic matter prevents losses of cadmium due to volatilization. Results obtained following the procedure described are accurate, and sufficiently precise. The method provided fast results (the sample was heated at $696 \mathrm{~W}$ for 2 minutes) and requires the sole use of nitric acid (2 mL).

\section{References}

1. Xiong, W. W.; Fisher, N. S. Mar. Biol. 1996, 125, 715-718.

2. Blanusa, M.; Breski, D. Talanta 1981, 28, 681-684.

3. Mckenzie, H. A.; Smythe, Ll. E. Quantitative Trace Analysis of Biological Materials, Elsevier, Amsterdam, 1988; p 353.

4. Luque de Castro, M. D.; da Silva, M. P. Trends Anal. Chem. 1997, 16, 16-24.

5. Tanner, P. A.; Leong, L. S. Anal. Chim. Acta 1997, 342, 247252.

6. Morales, A.; Pomares, F.; De La Guardia, M.; Salvador, A. $J$. Anal. Atom. Spectrom. 1989, 4, 329-332.

7. Sures, B.; Taraschewski, H.; Haug, C. Anal. Chim. Acta 1995, 311, 135-139.

8. Copa-Rodríguez, F. J.; Basadre-Pampín, M. I.; Fresenius, J. Anal. Chem. 1994, 348, 390-395.

9. Cespón-Romero, R. M.; Yebra-Biurrun, M. C.; BermejoBarrera, P. Anal. Chim. Acta 1996, 327, 37-45.

10. Reglamentación Técnico-Sanitaria de los Productos de la Pesca con Destino al Consumo Humano, Orden del 2-8-1991, B.O.E. No. 195 de 15 de agosto de 1991. 